\section{Emergências Psiquiátricas}

Quevedo J, Schmitt R, Kapczinski F, organizadores. Emergências Psiquiátricas. 2a ed. Porto Alegre: Artmed; 2008. 440 p.

O livro Emergências Psiquiátricas, lançado pelo Prof. Dr. João Quevedo, já se encontra em sua segunda edição. 0 autor, que é professor titular de Psiquiatria e coordenador do Programa de PósGraduação em ciências da saúde da Universidade do Extremo Sul Catarinense, apresenta em co-autoria com os Professores Ricardo Schmitt e Flávio Kapczinski esta importante publicação para a área médica, destinada principalmente aos profissionais que atuam em emergência.

Emergências Psiquiátricas é uma obra publicada pela editora Artmed. Após seis anos e muitas solicitações, os autores, com muita seriedade e propriedade, nos brindam com esta obra atualizada e de fácil manejo.

Contando com 45 colaboradores de vários Centros de Pesquisa no país, foram elaborados 20 capítulos. Ordenados de forma coerente, iniciam-se pela avaliação dos pacientes, trazendo conceitos, sugestões e precauções, instrumentalizando não apenas os médicos, mas todos os profissionais que trabalham nas equipes de atendimento de emergência.

Além de trazer muitas atualizações conceituais, o formato do texto ressalta importantes tópicos que conseguem visualmente se destacar.

O capítulo que trata da identificação e tratamento das emergências associadas ao álcool e drogas de abuso, escrito pelos colaboradores Raquel De Boni, Patrícia Saibro e Flávio Pechansky, todos médicos psiquiatras e pesquisadores da área, está especialmente interessante. Além de atualizado, traz vários quadros, tabelas e gráficos destacando informações preciosas de forma objetiva e de rápida identificação.

O algoritmo de decisão para internação psiquiátrica, contido no capítulo três, que aborda os aspectos ético-legais, é um instrumento claro e que dá segurança ao médico internante, principalmente ao médico não psiquiatra.

No momento atual, o manejo dos psicofármacos exige grandes conhecimentos referentes à farmacocinética, farmacodinâmica e às interações (leiam-se enzimas do citocromo P450). 0 capítulo que aborda a intoxicação e efeitos adversos graves dos psicofármacos traz na medida exata as informações essenciais para este tipo de atendimento.

O livro contempla ainda várias síndromes psiquiátricas e alguns transtornos específicos de grande interesse nesse tipo de atendimento, como o transtorno de pânico. Também orienta o atendimento em populações específicas, como crianças e adolescentes, idosos e gestantes.

Como capítulo final, os autores nos brindam com informações úteis na emergência psiquiátrica. Esquematizado na forma de gráficos, tabelas, endereços de referência, classificação diagnóstica segundo a CID-10 e descrição de psicofármacos, o texto encerra de forma objetiva este livro. Embora lembre muito um manual pelo formato e objetividade, aborda de forma mais ampla vários assuntos, dando segurança aos profissionais que venham a ele recorrer.

Vale comentar que uma obra de tal magnitude poderia conter partes de seu conteúdo em um CD, para que pudesse ser instalado em equipamentos de fácil acesso (palms, laptops e outros).

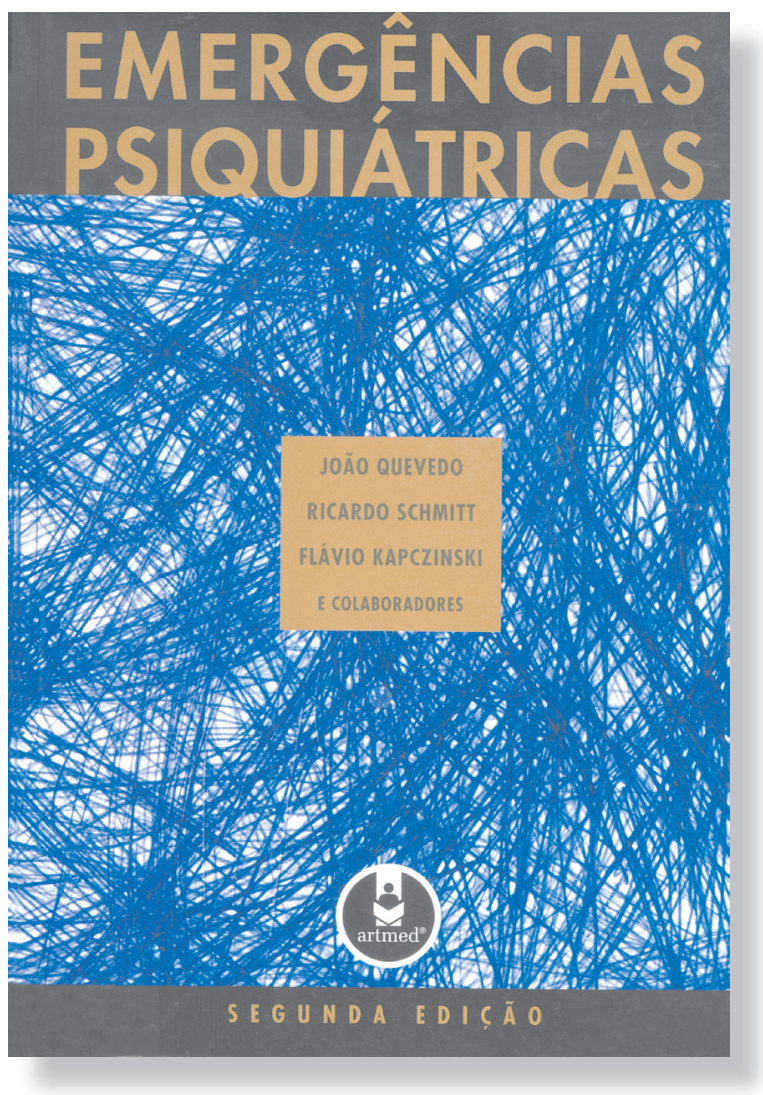

Ao fecharmos este livro tão bem concebido, o sentimento sobre ele é de admiração pela coerência e qualidade com as quais os autores realizaram sua obra. Com certeza não deverá faltar na biblioteca de quem maneja situações de emergência.

Celeste Corral Tacaci Neves Baptista

Preceptoria da Residência Médica em Psiquiatria do Hospital Universitário Dr. Domingos Leonardo Cerávolo, Presidente Prudente (SP), Brasil Faculdade de Medicina de Presidente Prudente (UNOESTE), Presidente Prudente (SP), Brasil Hospital Psiquiátrico Adolpho Bezerra de Menezes, Presidente Prudente (SP), Brasil 